\title{
A retail price index including the shadow price of owner occupied housing
}

\section{Laura Blow \\ Lars Nesheim}

The Institute for Fiscal Studies

Department of Economics, UCL

cemmap working paper CWP03/09 


\title{
A retail price index including the shadow price of owner occupied housing
}

\author{
Laura Blow Lars Nesheim \\ IFS CEMMAP \\ UCL and IFS
}

January 2009 


\begin{abstract}
How do house price changes affect the cost of living? The retail price index in the UK does not directly incorporate house price changes. Instead it uses mortgage interest to capture the cost of owning a home. This is a useful method from many perspectives. However, from a consumer welfare perspective, while mortgage interest does capture the cost of a particular service, it does not capture the cost of housing services. The shadow price of housing captures the welfare cost to a household of changes in housing prices. In this paper we create a new shadow price index using RPI data and the shadow price of housing and investigate how replacing the mortgage interest with the shadow price of housing affects measures of the cost of living.
\end{abstract}

JEL: C43, E31, R21

Keywords: housing, retail price index, shadow price, user cost Correspondence: 1.nesheim@ucl.ac.uk 1.blow@ifs.org.uk Acknowledgements: Financial support from the ESRC through research grant number RES-000-23-1448 and through the ESRC Centre for Microdata Methods and Practice (CEMMAP) (grant number RES-58928-0001) is gratefully acknowledged. All errors remain the responsibility of the authors. 


\section{Introduction}

How do house price changes affect the cost of living? This has always been a difficult question to answer for many reasons. One important reason is that housing is both a consumption good and an asset. Most government consumer price indexes explicitly seek to estimate the cost of a basket of consumption goods and therefore purposely exclude savings and investments. It is a difficult task to determine what portion of the cost of housing is consumption and what portion is investment.

Since January 1975, the estimate of owner-occupied housing costs included in the UK Retail Price Index (RPI) has been primarily based on an estimate of mortgage interest payments on a standard dwelling. In January 1995, an estimate of depreciation costs was added. As an alternative, the US consumer price index (CPI) uses an estimate of imputed rent derived from rental houses similar to owner-occupied housing. Both of these methods of incorporating housing costs in cost of living indexes are sensible methods, especially when statistical authorities must estimate monthly indexes like the RPI and the CPI. Both provide measures that can be calculated on a timely basis, that are easy to understand and to replicate and that are objective. Further, they capture a large portion of the direct expenditures that homeowners must make on housing.

However, cost of living indexes based on these housing cost measures are not the same as the ideal (constant utility) cost of living index (COLI) from economic theory. ${ }^{1}$ Nor are they the same as a Laspeyres cost of living index. They are not meant to be. See Boskin et al. (1996) for a discussion of a COLI versus a CPI or the RPI. The RPI is used as a macroeconomic indicator to measure inflation, for purposes of international comparisons ${ }^{2}$ and to deflate expenditures. It is also used to adjust tax allowances, to index incomes and pensions and benefits, and to index some gilts and savings. To meet these needs it must be continuously updated, reliable, replicable, objective and so on. The index as calculated has proved to be very valuable. Nevertheless, a true economic cost-of-living index is also desirable. By definition, it provides a measure of welfare that the RPI does not.

This discussion raises a crucial issue. How would one construct a

\footnotetext{
${ }^{1}$ Measures based on imputed rent are the same only if rental houses are identical in quality to houses owned by homeowners and if it is perfectly costless to move back and forth btween rental housing and owner-occupied housing. Neither of these conditions is satisfied in the UK. We discuss this further below.

${ }^{2}$ International comparisons can be difficult because different countries have different methods for estimating price indexes. For example, the treatment of housing costs varies significantly across countries. For comparisons within the EU, the RPI has been replaced by the Harmonised Index of Consumer Prices (HICP).
} 
constant utility COLI in a world with homeowners in a lifecycle model of housing investment? Or, alternatively how does one measure the price of housing services and the current "expenditure" on housing for owner-occupiers? From a theoretical welfare economics perspective, the answer is clear. Housing expenditures equal the "shadow price" of housing services (the marginal rate of substitution between housing services and non-durable consumption) multiplied by the quantity of housing services consumed. So, one must estimate the shadow price of housing.

In an idealised world, two simple measures of the shadow price are available. One is the user cost of housing capital. The other is the rental price of an equivalent rental house. Under very restrictive assumptions, both are equal to the shadow price of housing. ${ }^{3}$ Unfortunately, several factors lead to a divergence between these simple measures and the shadow price of housing. In particular, imperfect capital markets, risk aversion, the tax system and moving costs drive a wedge between the shadow price of housing and the user cost of housing. These factors and systematic differences between houses available in the rental and owner-occupied sectors, drive a wedge between rents and the shadow price. Rental equivalence is particularly untenable in the UK. The private rental market makes up only $8.5 \%$ of the entire housing market and quality differences between rental and owner occupied housing are stark. The rest of the rental market, $24 \%$ of the housing market as a whole, is made up of social housing. ${ }^{4}$ Thus, in real world housing markets, neither of the commonly used methods provide valid estimates of the shadow price of housing and expenditures on housing services by owner-occupiers.

Measuring the shadow price of housing correctly requires an understanding of consumer demand for housing as an asset and as a consumption good. Despite its importance, research in this area has been limited by computational and data problems. Until recently, the role of housing as an asset has only been studied in very simple models with two periods, in models with limited uncertainty, or in models with simple closed form solutions (Poterba (1992), Nordvik (2001), Ortalo-Magne and Rady (2002)). Empirical work has focused on testing some implications of housing models and impacts of housing price shocks and volatility without studying the full properties of lifecycle housing de-

\footnotetext{
${ }^{3}$ The RPI treatment of housing is based on the user cost idea. The US CPI treatment is based on the rental equivalence idea.

${ }^{4}$ Arevalo and Ruiz-Castillo (2006) use Spanish data to examine the quality of rental imputations in Spain. They find that, using Spanish data, the rental equivalence method can do a good job of estimating the shadow price of housing services for owner-occupiers.
} 
mand models (Muellbauer and Murphy (1997), Campbell and Cocco (2003), Attanasio, Blow, Hamilton, and Leicester (2004), Banks et al. (2004), Disney et al. (2004)). More recent theoretical work has begun to address these issues in realistic lifecycle models of housing demand (Campbell and Cocco (2007), Li and Yao (2007), Diaz and Luengo-Prado (2007), and Blow and Nesheim (2009).). In particular, using a computational model and US data Diaz and Luengo-Prado (2007) investigate biases to the US CPI that arise from using the rental equivalence approach. Using similar techniques, Blow and Nesheim (2009) calibrate a lifecycle model of housing demand with borrowing constraints and with stochastic house prices, income and real interest rates and show how to calculate the shadow price of housing.

In this paper we compare the RPI which uses mortgage interest payments to measure housing costs for homeowners to a "shadow RPI" or SPI that uses a measure of housing expenditure based on the shadow price of housing. To calculate the shadow price of housing and total expenditure on housing we use the simulation results from Blow and Nesheim (2009). In particular, we calculate time series of shadow prices of housing for eighteen demographic groups (nine birth cohorts born between 1900 and 1980 and two education groups (compulsory only and greater than compulsory). We use these shadow price series to calculate a shadow RPI or SPI. The SPI differs from the RPI because the weights differ and because the price series differ. We study the differences and discuss implications for measuring the welfare of homeowners.

\section{Shadow price of housing}

Blow and Nesheim (2009) derive formulas for the shadow price of housing in a dynamic lifecycle model of housing and consumption demand. Here we summarise their results.

The shadow price of housing is the price of housing services that would lead a consumer who could separately purchase housing services and a housing asset to consume the same amount of housing services as the consumer who purchases the bundled product. Suppose, at time $t$, a household chooses consumption $c_{t}$, housing $h_{t}$ and savings $s_{t}$ to solve

$$
\max _{\left\{s_{t}, c_{t}, h_{t}\right\}}\left\{\left(\frac{c_{t}^{a} h_{t}^{1-\alpha}}{\sigma}\right)^{\sigma}+\beta \int v\left(w_{t+1}, q_{t+1}, t+1\right) f\left(q_{t+1}\left|q_{t}\right|\right) d q_{t+1}\right\}
$$

subject to

$$
\left\{\begin{array}{c}
c_{t}+s_{t}+p_{t} h_{t}=w_{t} \\
w_{t+1}=r_{t+1} s_{t}+y_{t+1}+p_{t+1} h_{t} \\
s_{t} \geq-b_{y} y_{t} \\
s_{t} \geq-b_{h} p_{t} h_{t}
\end{array}\right\}
$$


where $w_{t}$ is wealth, $p_{t}$ is the price of housing, $r_{t}$ is the interest rate, and $y_{t}$ is income. The first constraint is the budget constraint, the second is the condition describing wealth in period $t+1$ as a function of savings and housing demand in period $t$ and income in period $t+1$. The final two constraints are liquidity constraints. The household can not borrow more than $b_{y}$ times income. Nor can they borrow more than a fraction $b_{h} \leq 1$ of their house value. Blow and Nesheim (2009) set up, calibrate and simulate solutions to this household lifecycle problem. The model incorporates uncertainty about house prices, interest rates and income as well as important features of the mortgage markets. All of these features have important impacts on the shadow price of housing and on household choices of consumption and housing.

Consider the shadow price of housing implied by this model. If $\left(c_{t}, h_{t}\right)$ are the optimal choices of a consumer solving problem (1), then the shadow price of housing, $\pi_{t}$, satisfies

$$
\pi_{t}=\frac{u_{h}\left(c_{t}, h_{t}\right)}{u_{c}\left(c_{t}, h_{t}\right)}
$$

where $u_{h}$ and $u_{c}$ are the derivatives of the utility function with respect to $h$ and $c$. This is the definition of a shadow price.

As shown in Blow and Nesheim (2009), we can also work out the shadow price from the first order conditions of (1). These first order conditions are somewhat complicated by then fact that one or both of the liquidity constraints in (2) may bind. Define $\lambda_{y t}$ and $\lambda_{h t}$ to be the Lagrange multipliers associated with the liquidity constraints in problem (1). The first order conditions from (1) imply that the shadow price $\pi_{t}$ satisfies

$$
\pi_{t}=p_{t}\left(1-\frac{\beta \int \frac{p_{t+1}}{p_{t}} \frac{\partial V\left(w_{t+1}, q_{t+1}, t+1\right)}{\partial w} f\left(q_{t+1} \mid q_{t}\right) d q_{t+1}+\lambda_{h t} b_{h}}{\beta \int r_{t+1} \frac{\partial V\left(w_{t+1}, q_{t+1}, t+1\right)}{\partial w} f\left(q_{t+1} \mid q_{t}\right) d q_{t+1}+\lambda_{y t}+\lambda_{h t} b_{h}}\right) .
$$

The shadow price depends on the house price $p_{t}$, on the covariance of $\frac{p_{t+1}}{p_{t}}$ and future marginal utility $\left(\frac{\partial V}{\partial w}\right)$, on the covariance of future interest rates with marginal utility, and on the Lagrange multipliers from the liquidity constraints. From this formula one can see that the shadow price is not equal to the mortgage interest rate. Nor is it equal to the user cost of housing for an unconstrained borrower. The user cost of 
housing for an unconstrained borrower in this model is

$$
\pi_{t}=p_{t}\left(1-\frac{\int \frac{p_{t+1}}{p_{t}} f\left(q_{t+1} \mid q_{t}\right) d q_{t+1}}{\int r_{t+1} f\left(q_{t+1} \mid q_{t}\right) d q_{t+1}}\right) .
$$

For those who are unconstrained, the shadow price differs from the user cost because people are risk averse. In addition, for constrained households, an additional difference is caused by binding constraints.

To calculate a cost of living index based on the shadow price, one must compute solutions to model (1) and calculate the shadow prices using either (3) or (4). Note that even when households have exactly the same utility functions, the shadow price will vary across households who choose different quantities of $\left(c_{t}, h_{t}\right)$ due to differences in age, wealth, birth cohort, education or family size.

Blow and Nesheim (2009) simulate lifecycle profiles of $\left(c_{t}, h_{t}\right)$ and of $\pi_{t}$ for 18 groups, 9 cohorts $(1900,1910, \ldots, 1980)$ and two education groups in each cohort. They first estimate time series processes for house prices $p_{t}$ and interest rates $r_{t}$. Then, for each cohort and education group, they estimate time series processes for income. Finally using parameters from the literature, they calibrate initial values of wealth for each group so that predicted average house values from the model match average house values in the FES from 1990 to 2000 . The calibration data from that study are replicated here in Table 1 . The table shows average house values and average consumption for each cohort and education group in for the period 1992 to 1999.

Using the calibrated model of Blow and Nesheim (2009), in this paper we simulate 1000 households in each group and calculate the median values of $\pi_{t}$ to produce time series of cohort specific shadow prices. The average across cohorts of our median shadow price series is shown in Figure 1. The figure also shows time series for the mortgage interest rate used to calculate mortgage interest payments in the RPI.

The shadow price series behaves very differently from the mortgage interest rate series. From 1988 to 1992 when the mortgage interest rate increased from 1 to over 2, the shadow price decreased from 1 to 0.4 . During this period interest rates were rising while housing prices were falling dramatically. Note however, that from 1994 onward, the shadow price did not increase even though house prices were increasing. It seems that expectations of future house price growth kept the shadow price low. By 2003, the shadow price was still one half its level in 1988.

In the following sections, we investigate how a cost of living index based on this shadow price of housing compares with the RPI based on 
the mortgage interest price series. First we describe a bit more about the RPI and how it is calculated.

\section{Price index: RPI}

The UK Retail Price Index (RPI) is "defined as the average measure of change in the price of goods and services bought for the purpose of consumption." (See RPI Manual (1998)). It is produced by the Office of National Statistics and is used to measure changes in the prices of a fixed basket of goods. Its history and details of its construction is summarised in the RPI Manual (1998).

The British government began systematically and continuously to monitor the cost of living in 1914 and the first official RPI was published in January 1956. Through the years the index has changed as data availability changed and as the economy changed. In particular, the treatment of housing has changed over time. A measure of housing costs was first added to the index in January 1956. In the 1960s and 1970s, there were various changes to the calculation of owner-occupier housing costs including a new method of calculating mortgage interest payments from 1975 which replaced an equivalent rents approach.

The current treatment of housing costs dates from 1987. Then, in response to the recommendations of an advisory committee, housing costs came to be measured as mortgage interest payments and maintenance plus council tax. A further change in 1995 led to the measurement of depreciation.

We do not fully calculate a true cost-of-living index since differences between such an index and the RPI would be due both to replacing the published mortgage interest payments price with our shadow price and to other differences between a fixed-weight index (such as the RPI) and a true cost-of-living index. Rather, we first use ONS published prices and weights to replicate the RPI, and we then calculate a new SPI by replacing the price of mortgage interest payments, which also necessitates an adjustment to the weights. We describe the necessary calculations in more detail in the next section.

\section{Calculation of the RPI}

Technically, the RPI is calculated as follows. Within a year, the monthly (or month to month) RPI is a weighted average of the relative prices of a basket of commodities across two months. For each commodity, the weight chosen corresponds to the mean proportion of total spending accounted for by that commodity. The weights are calculated using data principally from the Family Expenditure Survey (FES)/Expenditure and 
Food Survey (EFS) but also from other sources.

Consider the monthly RPI for the year $t$. Weights for each commodity are calculated using average consumer expenditure data from July in the year $t-2$ to June in year $t-1$ expressed in January of year $t$ prices. ${ }^{5}$ For example, the weights used in the 1999 RPI are calculated using spending data from July 1997 to June 1998 expressed in January 1997 prices. Therefore the RPI in month $m$ in year $t$ based in January of year $t$ (denoted $R P I_{t, m}$, where $\left.m=1,2, \ldots, 12,13\right)^{6}$ is given by

$$
R P I_{t, m} \equiv \frac{\sum_{i=1}^{N} p_{t, m}^{i} \bar{q}_{t}^{i}}{\sum_{i=1}^{N} p_{t, 1}^{i} \bar{q}_{t}^{i}},
$$

where $\bar{q}_{t}^{i}$ is the average quantity of good $i$ consumed in the the year $t$ base period (i.e. July in year $t-2$ to June in year $t-1$ ) and $p_{t, m}^{i}$ is the price of good $i$ in month $m$ in year $t$. For example, $p_{t, 1}^{i}$ is the price of good $i$ in January of year $t$.

The formula in (6) can be rewritten as

$$
R P I_{t, m}=\sum_{i=1}^{N}\left(\frac{p_{t, m}^{i}}{p_{t, 1}^{i}}\right) w_{t}^{i}
$$

where

$$
w_{t}^{i}=\frac{p_{t, 1}^{i} \bar{q}_{t}^{i}}{\sum_{i=1}^{N} p_{t, 1}^{i} \bar{q}_{t}^{i}} .
$$

Equation (7) shows that the within-year RPI in month $m$ is a weighted average of the prices in month $m$ relative to January prices. For each good, the weight is the base period budget share of the good. For year $t$, base expenditures are calculated using quantities from July in $t-2$ to June in year $t-1$ expressed in January of year $t$ (i.e. the current year) prices.

The weights in (7) are calculated using data from the FES/EFS. However, it is not possible to use the FES/EFS and formula (8) directly

\footnotetext{
${ }^{5}$ As discussed in the RPI Manual (1998), average expenditures for a year are used to compute the weights for several reasons. First, this eliminates seasonal effects. Second, it reduces fluctuations caused by short term variations in spending. Third, it is impossible to obtain up-to-date expenditure data without allowing some lag time for data collection and data processing.

${ }^{6}$ As discussed in section 4.1, the within-year RPI is calculated for 13 months so that consecutive years can be chained together. Thus, $R P I_{t, 13}$ is the RPI for January in year $t+1$ using January in year $t$ as a base. We describe chaining of consecutive years in 4.1 .
} 
because the FES/EFS records expenditures not quantities. Instead, $p_{t, 1}^{i} \bar{q}_{t}^{i}$ must be constructed from the FES/EFS using average expenditures. Denote average expenditure on good $i$ in the base period for year $t$ (i.e. from July in year $t-2$ to June in year $t-1$ ) by $e_{t}^{i}$. This is the information that is recorded in the FES/EFS. Then $p_{t, 1}^{i} \bar{q}_{t}^{i}$ is calculated as

$$
\bar{e}_{t}^{i}=p_{t, 1}^{i} \bar{q}_{t}^{i}=\frac{p_{t, 1}^{i}}{p_{t-1,1}^{i}} e_{t}^{i}
$$

Thus the FES/EFS and the relative price data from the ONS can be used to construct an approximate RPI using the two formulas (7) and (9) .

\subsection{Chaining}

The above formulas are used to construct the month to month RPI within a year. Within a year, the weights are held fixed. However, between years the basket used to construct the RPI changes. To link within-year RPI calculations across years, a procedure called chaining is used. To construct a year to year RPI, the within-year RPI's are chained together. Between years, the RPI is a chained index. Formally, the RPI in month $m$ in year $t$ based in January of year $s<t$ is

$$
R P I_{t, m, s}=R P I_{t, m} \times \prod_{j=s}^{t-1} R P I_{s, 13}
$$

where, as above, $R P I_{s, 13}$ is the RPI in month 13 of year $s$ (i.e. January of year $s+1$ calculated using weights from year $s$.)

\subsubsection{Items included in RPI}

Although much of the spending data used to calculate the RPI weights comes from the FES/EFS, some does not. For example, spending on tobacco, alcohol, soft drinks and confectionery, purchase of motor vehicles, and, importantly, some housing costs are not calculated based on the FES/EFS. For owner-occupiers, the housing costs included in the RPI are mortgage interest payments (MIPs), depreciation and council tax payments (CTPs). Capital repayments are excluded. The MIPs are calculated using a model which calculates the interest payments due on a 23-year repayment mortgage taken out on an averagely priced house this month and up to 275 months ago (see the RPI Manual (1998) for details). Depreciation costs are meant to capture the cost of maintaining a constant quality house. They are calculated based on a smoothed time series of the market value of the UK housing stock multiplied by a depreciation factor of $1.4 \%$ (taken from national accounts data). Council 
tax payment expenditures are based on average council tax payments adjusted using data from the EFS/FES.

We cannot duplicate the RPI precisely. Instead, we compare an index that is calculated in the same way as the RPI using MIPs, depreciation and CTPs with an index that uses the shadow price of housing, depreciation and CTPs. Both are fixed basket price indexes. The former is much less costly to calculate and can be calculated based on data available to the ONS on a monthly basis. As such it is a practical index that can be used for all the required uses of the RPI. However, the latter is more closely akin to a Laspeyres price index that approximates a constant utility cost of living index because it uses the quantity of housing consumed and the shadow price of housing. As such it, provides a better measure of consumer welfare than the RPI.

\subsection{Empirical RPI}

Let $\left(w_{t}^{M}, p_{t, m}^{M}, \bar{q}_{t}^{M}\right)$ be the weights, prices and quantities corresponding to MIPs. The RPI is

$$
R P I=\sum_{i=1}^{N-1}\left(\frac{p_{t, m}^{i}}{p_{t, 1}^{i}}\right) w_{t}^{i}+w_{t}^{M}\left(\frac{p_{t, m}^{M}}{p_{t, 1}^{M}}\right)
$$

where

$$
\begin{aligned}
w_{t}^{i}= & \frac{p_{t, 1}^{i} \bar{q}_{t}^{i}}{\sum_{i=1}^{N-1} p_{t, 1}^{i} \bar{q}_{t}^{i}+p_{t, 1}^{M} \bar{q}_{t}^{M}} \\
w_{t}^{M}= & \frac{p_{t, 1}^{M} \bar{q}_{t}^{M}}{\sum_{i=1}^{N-1} p_{t, 1}^{i} \bar{q}_{t}^{i}+p_{t, 1}^{M} \bar{q}_{t}^{M}}
\end{aligned}
$$

The published RPI price indexes and weights contain data on $\left(w_{t}^{i}, \frac{p_{t, m}^{i}}{p_{t, 1}^{i}}\right)$ and $\left(w_{t}^{M}, \frac{p_{t, m}^{M}}{p_{t, d}^{M}}\right)$. From this information we can replicate an RPI calculation. Our aim is then to compare the RPI to a Shadow Price Index (SPI) where the only change we make is to replace the mortgage interest component of the RPI with housing expenditure based on an estimate of the shadow price of housing and of the quantity of housing services consumed. This will change all the weights used in the index calculation by changing the total budget (the denominator in equation (8)). Our new SPI is

$$
S P I=\sum_{i=1}^{N-1}\left(\frac{p_{t, m}^{i}}{p_{t, 1}^{i}}\right) \widetilde{w}^{i}+\widetilde{w}^{H}\left(\frac{p_{t, m}^{H}}{p_{t, 1}^{H}}\right)
$$




$$
\begin{gathered}
\widetilde{w}_{t}^{i}=\frac{\bar{e}_{t}^{i}}{\sum_{i=1}^{N} \bar{e}_{t}^{i}+p_{t, 1}^{H} \bar{q}_{t}^{H}} \\
\widetilde{w}_{t}^{H}=\frac{p_{t, 1}^{H} \bar{q}_{t}^{H}}{\sum_{i=1}^{N} \bar{e}_{t}^{i}+p_{t, 1}^{H} \bar{q}_{t}^{H}} .
\end{gathered}
$$

where we estimate $\bar{e}_{t}^{i} \equiv p_{t, 1}^{i} \bar{q}_{t}^{i}$ for $i=1, \ldots, N-1$ from the FES/EFS as given in equation (9).

\section{Results}

Table 2 and Figure 2 show our estimates of the annual RPI and the annual SPI from 1988 to 2003. The time period is limited to this range due to data limitation and our price index is currently limited to the annual level due to computational limitiations. A model period in the simulation model is currently one year long. As a results the simulation model produces estimates of the shadow price of housing at the annual level. Relative to the SPI, the RPI significantly overstates the constant utility cost of living during this period. Much of this difference can be attributed to the big drop in the shadow price index from 1989 to 1992, a drop that paralleled the drop in housing prices during this period.

There are also significant differences in the weights on mortgage interest payments in the RPI and the weights on shadow prices in the SPI. Figure 4 shows the time series of weights for both MIPs in the RPI and for the shadow price in the SPI. The weights on MIPs during this period reach a maximum of about 0.07 in 1990 and hover around 0.04 throughout the period while the weights on the shadow price in the SPI are around 0.14 . The 0.14 number results directly from our assumption that $\alpha=0.8$ in the utility function. Since $\alpha=0.8$, the within-period budget share of housing for a homeowning household is 0.2. During the period of study the homeowner share of the UK population ranged from 0.66 to 0.71 . These two numbers determine the weight on the shadow price: $0.7 * 0.2=0.14$. The budget share assumption is taken from $\mathrm{Li}$ and Yao (2007) who base their number on the budget share of housing for renters in the US. In the UK, the budget share of housing for private renters in the $2002 \mathrm{FES}$ was $33 \%$ suggesting that the value of $1-\alpha=0.2$ is too low for the UK. We chose the higher number to be conservative. In any case, comparison of the weights in Figure 4 with US data or with UK budget share data, suggests that the weights on housing expenditures in the UK RPI are too low.

Finally, Figure 3 displays the annual inflation rates implied by the RPI and the SPI. Both series display volatility. However, the volatility 
moves in different directions. This suggests that the RPI neither captures long term trends in the cost of owner-occupied housing nor does it capture annual fluctations.

\section{Conclusions}

While the specific year-to-year price changes we calculate depend heavily on the modeling assumptions in Blow and Nesheim (2009), it is clear that a cost of living index that does not incorporate housing price changes provides highly misleading estimates of the cost of living for homeowners. First, housing makes up a large share of the household budget. In fact, the weights on housing costs in our SPI are much larger than the weights on MIPs in the RPI. It seems that the RPI significantly understates the contribution of housing costs to the cost of living. Second, the price of housing services is not simply a function of housing prices nor of interest rates. Rather it is a function of both housing prices and interest rates as well as other factors such as household beliefs about future house prices and interest rates, household preferences towards housing and toward risk, and the importance of liqidity constraints in the economy. The precise numerical results in this paper depend on the modeling assumptions in our lifecycle model. In particular, different assumptions about household preferences towards housing and risk or about household beliefs about future housing prices and interest rates would lead to different price series. Nevertheless, it is possible to ground the results using data on consumption expenditures and housing expenditures. More work needs to be done to test the robustness of our results with respect to these modeling assumptions and to produce better estimates of household preferences. Also, more work needs to be done to incorporate features into the model such as transaction costs, taxes, depreciation and maintenance. Díaz, Antonia, and Luengo-Prado, María José (2007) incorporate these features into their model of housing consumption in the US at the cost of less precision in their computational work and less richness in the stochastic environment. For instance, they do not incorporate stochastic interest rates in their model. A merged approach that adds these features while preserving computational precision and the stochastic environment is promising. 
Table 1:

House values and annual consumption (1992 - 1999):

FES cohort averages

\begin{tabular}{|ccccc|}
\hline Age & Cohort & Education & C & V \\
\hline 91 & 1900 & 0 & $£ 6,340$ & $£ 93,500$ \\
91 & 1900 & 1 & $£ 9,570$ & $£ 162,000$ \\
81 & 1910 & 0 & $£ 8,370$ & $£ 82,900$ \\
81 & 1910 & 1 & $£ 11,500$ & $£ 127,000$ \\
71 & 1920 & 0 & $£ 11,600$ & $£ 78,200$ \\
71 & 1920 & 1 & $£ 15,800$ & $£ 123,000$ \\
61 & 1930 & 0 & $£ 16,300$ & $£ 78,700$ \\
61 & 1930 & 1 & $£ 22,700$ & $£ 122,000$ \\
51 & 1940 & 0 & $£ 21,300$ & $£ 81,500$ \\
51 & 1940 & 1 & $£ 28,100$ & $£ 125,000$ \\
41 & 1950 & 0 & $£ 21,700$ & $£ 80,200$ \\
41 & 1950 & 1 & $£ 26,100$ & $£ 113,000$ \\
31 & 1960 & 0 & $£ 19,400$ & $£ 71,200$ \\
31 & 1960 & 1 & $£ 22,500$ & $£ 90,400$ \\
21 & 1970 & 0 & $£ 17,000$ & $£ 57,400$ \\
21 & 1970 & 1 & $£ 19,300$ & $£ 65,500$ \\
\hline
\end{tabular}


Table 2:

Comparison of RPI and SPI

\begin{tabular}{|c|cc|cc|}
\hline & \multicolumn{2}{|c|}{ RPI vs SPI } & \multicolumn{2}{c|}{ RPI inflation vs SPI inflation } \\
\hline Year & RPI & SPI & RPI inflation & SPI inflation \\
\hline 1988 & 1 & 1 & & \\
1989 & 1.0735 & 1.148 & 0.0735 & 0.148 \\
1990 & 1.1544 & 1.2975 & 0.0754 & 0.1302 \\
1991 & 1.257 & 1.4322 & 0.0888 & 0.1038 \\
1992 & 1.312 & 1.433 & 0.0438 & 0.0006 \\
1993 & 1.3351 & 1.3899 & 0.0176 & -0.0301 \\
1994 & 1.3679 & 1.4097 & 0.0246 & 0.0142 \\
1995 & 1.4114 & 1.4762 & 0.0318 & 0.0472 \\
1996 & 1.4511 & 1.526 & 0.0281 & 0.0337 \\
1997 & 1.4877 & 1.5449 & 0.0252 & 0.0124 \\
1998 & 1.5332 & 1.658 & 0.0306 & 0.0732 \\
1999 & 1.5672 & 1.6858 & 0.0222 & 0.0168 \\
2000 & 1.5939 & 1.72 & 0.017 & 0.0203 \\
2001 & 1.6274 & 1.8474 & 0.021 & 0.0741 \\
2002 & 1.6435 & 1.7467 & 0.0099 & -0.0545 \\
2003 & 1.6766 & 1.817 & 0.0201 & 0.0402 \\
\hline
\end{tabular}




\section{References}

[1] Arévalo, Raquel, and Ruiz-Castillo, Javier (2006), "On the Imputation of Rental Prices to Owner-Occupied Housing," Journal of the European Economic Association, 4(4): 830-61.

[2] Blow, Laura, and Nesheim, Lars (2009), "A Lifecycle Model of Consumption, Savings, and Housing," CEMMAP working paper.

[3] Boskin, M.J. and Dulberger, E.R. and Gordon, R.J. and Griliches, Z. and Jorgenson, D. (1996), "Toward a More Accurate Measure of the Cost of Living," Final Report to the Senate Finance Committee from the Advisory Commission to Study the Consumer Price Index.

[4] Campbell, John and Cocco, João (2007), "How Do House Prices Affect Consumption: Evidence from Microdata," Journal of Monetary Economics, 54: 591-621.

[5] Crawford, I. (1994), "UK household cost-of-living indices, 19791992", Institute for Fiscal Studies Commentary C44.

[6] Díaz, Antonia, and Luengo-Prado, María José (2007), "On the User Cost and Homeownership," Review of Economic Dynamics, 11: 584613.

[7] Li, Wenli and Yao, Rui (2007), "The Life-Cycle Effects of House Price Changes," Journal of Money, Credit and Banking, 39(6): 1375-1409.

[8] Office for National Statistics (1998), The Retail Prices Index: Technical Manual, ed. Michael Baxter, 1998 Edition, The Stationery Office: London, 1998.

[9] Poterba, J. (1992), "Taxation and Housing: Old Questions, New Answers," The American Economic Review, 82(2): 237-242.

[10] Robinson, B. and Skinner, T. (1989), "Reforming the RPI: a better treatment of housing costs" 
Figure 1: Housing Shadow Price vs. Mortgage Interest Price

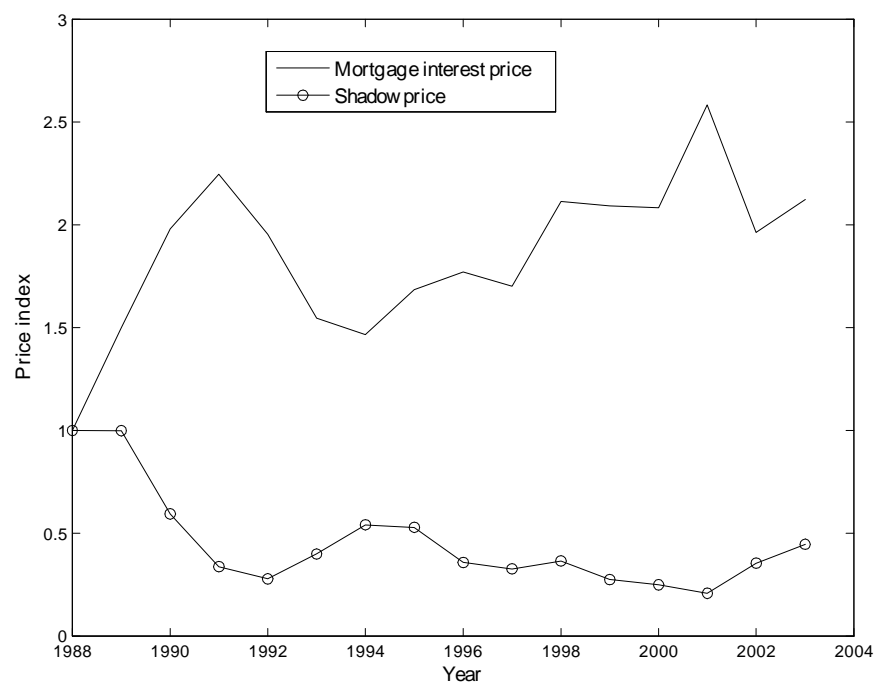

Figure 2: RPI vs. SPI

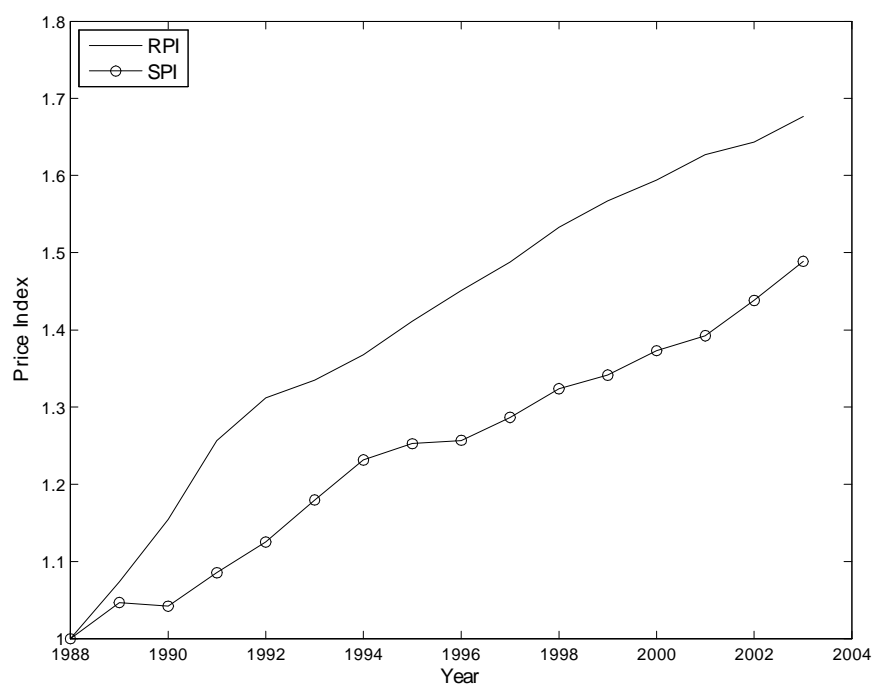


Figure 3: RPI Inflation vs. SPI Inflation

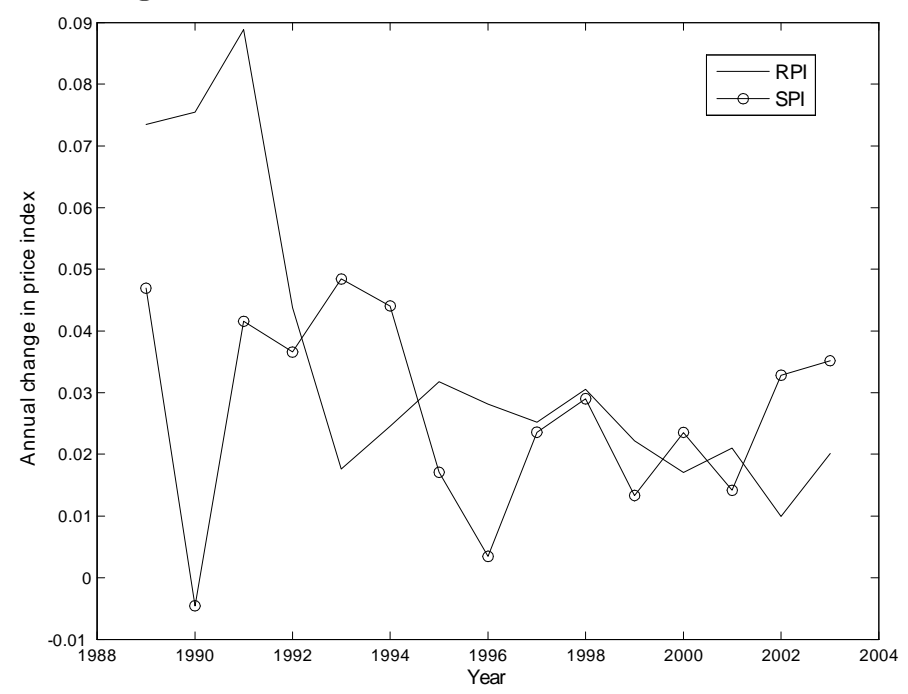

Figure 4: Housing weights: MIPs vs Shadow Price

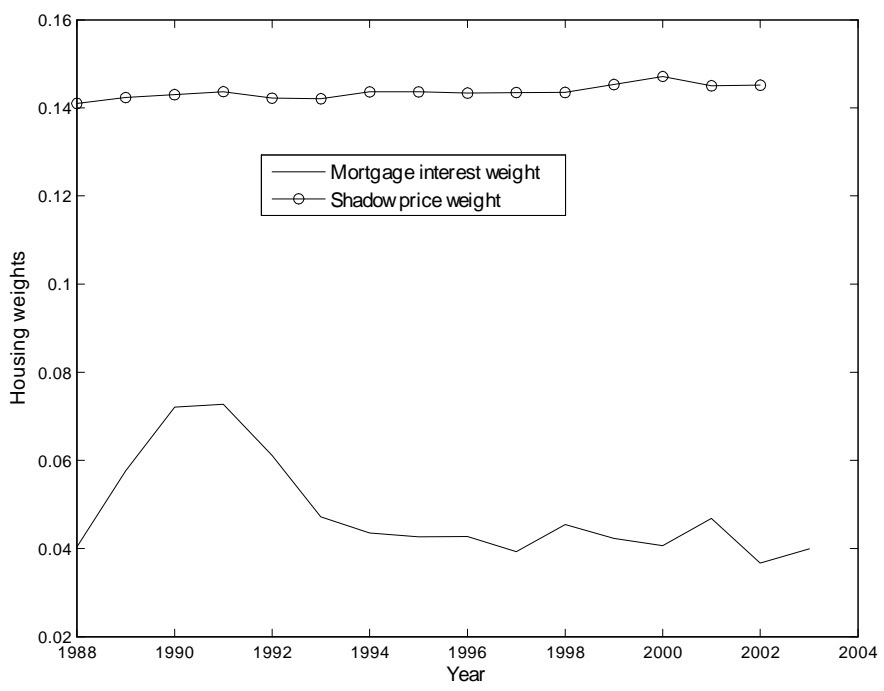

